\title{
Rotura de Tendón Aquíleo asociada a Levofloxacino
}

\author{
Marco Antonio Esquivias Camposª, María del Carmen Álvarez Galánº, Javier Massó Orozco
}

\begin{abstract}
${ }^{a}$ Residente de Medicina
Familiar y Comunitaria.

Unidad Docente de Albacete.

${ }^{\mathrm{b}}$ Médico de Familia. Hospital General de Villarrobledo (Albacete).

c Médico de Familia. Centro de Salud de Alatoz (Albacete).
\end{abstract}

Correspondencia: Marco Antonio Esquivias Campos, Avda. de la Mancha $n^{\circ} 77$, Bloque D, Portal 2, $3^{\circ} \mathrm{B}$, 02006 - Albacete,

España. Telf.: 616075623, correo electrónico: maesquiviasc@yahoo.com

Recibido el 4 de septiembre de 2009.

Aceptado para su publicación el 26 de septiembre de 2009.

\section{RESUMEN}

El uso de fluorquinolonas y el riesgo asociado de tendinitis aquílea está bien documentado, pero su prescripción en la práctica clínica es común ${ }^{1,2}$. Presentamos el caso de un paciente con tendinitis aquílea y posterior rotura a los pocos días de haber finalizado el tratamiento con levofloxacino por infección respiratoria. El diagnóstico temprano y la suspensión del tratamiento son fundamentales porque se podría prevenir el riesgo de rotura del tendón ${ }^{3,4}$.

Palabras clave. Tendinopatía. Levofloxacino. Efectos Adversos.

\section{ABSTRACT}

Levofloxacin-related Achilles tendon rupture

The use of fluoroquinolones and the associated risk of Achilles tendinitis is well-documented however this drug is commonly prescribed in clinical practice ${ }^{1,2}$. We describe a case of Achilles tendinitis and subsequent tendon rupture a few days after taking levofloxacin for a respiratory infection. Early diagnosis and treatment cessation are essential for preventing the risk of tendon rupture ${ }^{3,4}$.

Key words. Tendinopathy, Levofloxacin, Adverse Effects.

\section{INTRODUCCIÓN}

A pesar que el levofloxacino es un fármaco seguro y con mejor eficacia microbiana comparado con las primeras quinolonas, se asocia cada vez más a tendinitis en múltiples localizaciones con riesgo potencial de originar rotura de tendón, sobretodo en pacientes con edad avanzada, terapia crónica con esteroides, insuficiencia renal crónica o enfermedades reumatológicas ${ }^{5,6}$.

\section{OBSERVACIONES CLÍNICAS}

Paciente varón de 87 años con antecedentes de hipertensión arterial, insuficiencia cardiaca congestiva, EPOC, insuficiencia renal crónica e hipotiroidismo iatrogénico. En tratamiento con suplementos de potasio, omeprazol y hormona tiroidea. Ingreso hospitalario por proceso respiratorio que precisó tratamiento con levofloxacino 500 $\mathrm{mg} / 24 \mathrm{~h}$ (14 días) y pauta descendente de corticoides.

A los 5 días de terminar la pauta antibiótica consultó con el médico de Atención Primaria por dolor en ambas piernas desde el alta hospitalaria que progresivamente le dificultaba la deambulación. Se evidenciaron intensos edemas maleolares y pretibiales con dolor en región tibial posterior derecha, empastamiento a dicho nivel y pulsos periféricos conservados. Se derivó e ingresó en el hospital de referencia, constatándose dicha afectación.

Analítica: Hb 11.7 gr/dl, VCM 86 fL, hemograma normal, VSG 27, PCR 23, TSH 40.54 $\mathrm{uU} / \mathrm{mL}$, T4 0.44, ASLO, factor reumatoideo, ANA, anticuerpos antimitocondriales, antimicrosomas, antimusculo liso, antireticulina, anticitoplasma neutrófilo, ENAS y antiperoxidasa negativos. En ecodoppler de miembros inferiores no se objetivaron signos de TVP. La ecografía tendinosa (figura 1) y la resonancia magnética de tobillo derecho 
(figura 2) confirmaron rotura parcial de tendón aquíleo derecho y tendinitis aquílea y supraespinosa izquierdas. Se pautó tratamiento con AINES, alta con reposo relativo y posterior deambulación con bastón.

\section{COMENTARIOS}

Por su amplio espectro antibiótico, perfil de seguridad y biodisponibilidad, la prescripción de levofloxacino es muy frecuente desde Atención Primaria y especialidades hospitalarias al tratar infecciones bacterianas urinarias, dérmicas y principalmente respiratorias ${ }^{7}$. Ha sido incluido como fármaco de primera línea en los consensos de tratamiento empírico de neumonía adquirida en la comunidad y de reagudizaciones de EPOC $^{8}$.

La asociación entre el uso de fluorquinolonas y tendinitis aquilea no es frecuente, pues se estima una incidencia de 15 a 20 casos/ 100.000 tratamientos, pero está ampliamente documentada ${ }^{5}$. Los efectos reumatológicos adversos son tendinopatías, artralgias y mialgias.

El mecanismo por el que se produce afectación tendinosa es desconocido ${ }^{7}$, aunque se postula la pérdida de colágeno y proteoglicanos como secuela temprana de degeneración del tenocito ${ }^{9}$. Se reconocen como factores de riesgo el ser varón (3:1), mayor de 60 años en tratamiento habitual con corticoides (6:1), insuficiencia renal, fragilidad tendinosa por cualquier etiología y, sobretodo, la exposición recurrente al fár$\operatorname{maco}^{10}$.
Hemos presentado el caso de un paciente habitual en nuestras consultas de atención primaria o en las guardias hospitalarias, afectado por insuficiencia renal crónica y EPOC, que ha precisado tratamientos ambulatorios e ingresos hospitalarios en anteriores oportunidades por infecciones respiratorias de vías inferiores, tratado preferentemente con levofloxacino y pautas cortas de corticoides.

Siguiendo el algoritmo de Karch y Lasagna (relación de causalidad entre fármaco y efecto adverso) ${ }^{4}$, consideramos que este paciente cumple con el diagnóstico presuntivo de tendinitis y rotura de tendón aquíleo por levofloxacino por: a) secuencia temporal compatible con el comienzo del tratamiento con fluorquinolonas (variable, desde pocas horas a dos meses), b) se excluyen otras causas de afectación de tendones, tanto traumáticas como atraumáticas (síndrome SR3PE con hipotiroidismo autoinmune, artritis reumatoide, LES), c) se objetivó mejoría sintomática aunque no se pudo valorar reversión al suspender levofloxacino (suele revertir entre 10 días y 2 meses, evitando la rotura del tendón) $)^{3,4}$ y d) es un efecto adverso ya conocido de las fluorquinolonas en pacientes con factores de riesgo asociados.

Por último, cabe mencionar que no hay estudios experimentales en nuestro medio principalmente por motivos éticos y la mayor aportación al tema son cartas al editor y casos clínicos aislados. A pesar de esta limitación, el médico tratante debe tomar en cuenta esta entidad al prescribir fluorquinolonas ${ }^{1}$.

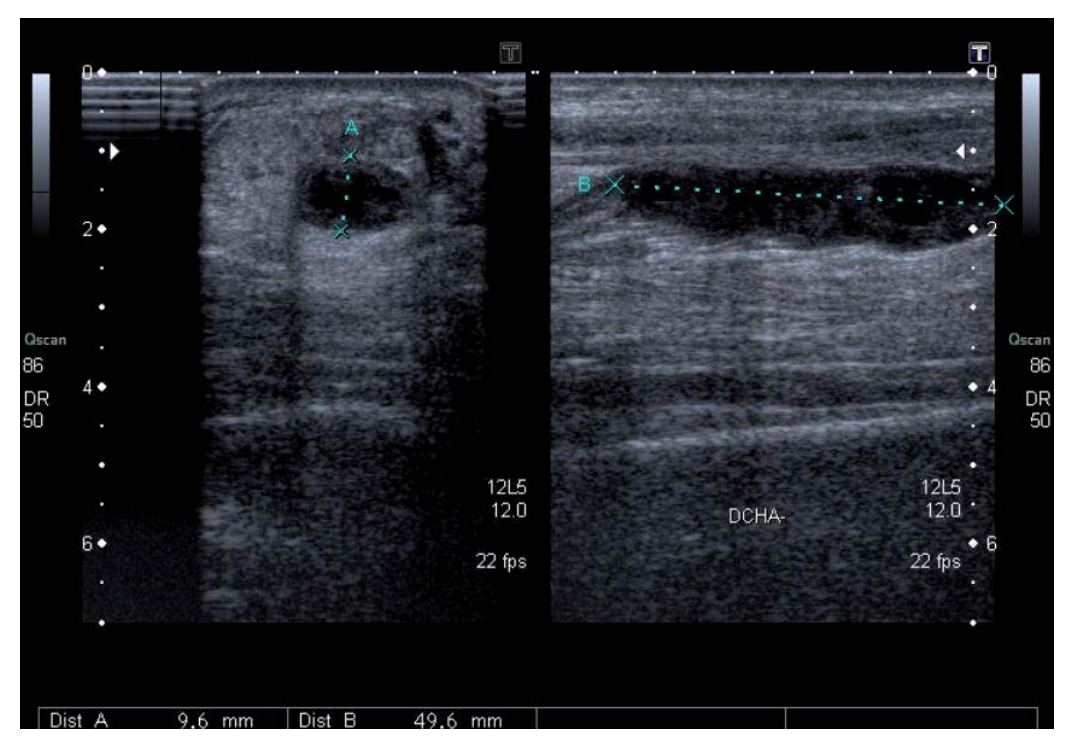

Fig. 1. Ecografia tendinosa: rotura parcial de tendón de aquiles derecho con hematoma importante intramuscular. Tendinitis leve a nivel aquileo izquierdo y del supraespinoso izquierdo. 


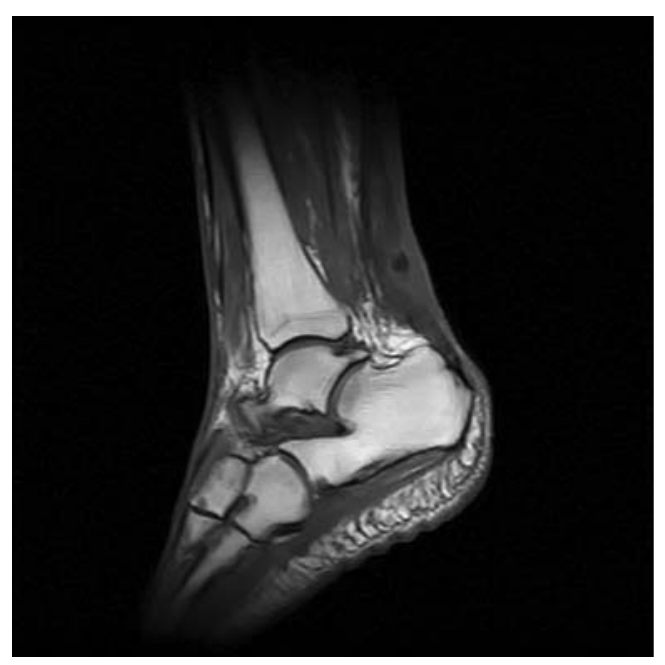

Figura 2. RMN de tobillo derecho: rotura de porción distal de tendón aquíleo. Edema subcutaneo importante y hematoma intramuscular. Tenosinovitis del tibial posterior.

\section{BIBLIOGRAFÍA}

1. Sánchez L, Sanjuán F, Naya J, Castiella J. Levofloxacino y rotura bilateral del tendón de Aquiles con evolución fatal. An Med Interna (Madrid) 2006; 23:102.

2. Sode J, Obel N, Hallas J, Lassen A. Use of fluorquinolone and risk of achilles tendon rupture: a population-based cohort study. Eur J Clin Pharmacol 2007; 63(5):499-503.

3. Nuño F, Noval J, Suarez M, Guinea O. Dolor aquíleo e impotencia funcional en paciente con enfermedad obstructiva crónica con neumonía. Rev Clin Esp 2001; 201:539-40.

4. Lado F, Rodríguez C, Velasco C, Durán C, Moar B. Rotura parcial bilateral aquílea asociada a levofloxacino. An Med Interna (Madrid) 2005; 22:28-30.

5. Medrano M, Mauri J, Bruscas C. Tendinitis por fluorquinolonas. An Med Interna (Madrid) 2007; 24:227-30.

6. Van der Linden P, Sturkenboom M, Herings R, Leufkens $H$, Rowlands S, Stricker B. Increased risk of achilles tendon rupture with quinolone antibacterial use, especially in elderly patients taking oral corticosteroids. Arch Intern Med 2003; 163(15):1801-7.

7. Gómez N, Ibáñez J, González M. Tendinitis aquílea bilateral y levofloxacino. An Med Intern (Madrid) 2004; 21(3):154.

8. Grupo de estudio de la Neumonía Adquirida en la Comunidad. Normativas para el diagnóstico y el tratamiento de la neumonía adquirida en la comunidad. Sociedad Española de Neumología y Cirugía Torácica (SEPAR). Arch Bronconeumol 2005; 41:27289.

9. Guis S, Bendahan D, Kozak-Ribbens G, Mattei J, Le Fur Y, Confort-Gouny S. Investigation of fluorquinolone-induced myalgia using 31P magnetic resonance spectroscopy and in vitro contracture tests. Arth Rheum 2002; 46:774-8.

10. Fernández E, Páramo de Vega M, Cabarcos A, Touceda A, Cigarrán B, Torre J. Afectación bilateral del tendón de Aquiles por tratamiento con levofloxacino. An Med Interna (Madrid) 2007; 24(7):359. 